\title{
Effect of Measurement Factors on Photovoltaic Cell Parameters Extracting
}

\author{
El Hadi Chahid ${ }^{1}$, Mohammed Idali Oumhand ${ }^{2}$, M'barek Feddaoui $^{3}$, Mohammed Erritali ${ }^{4}$, \\ Abdessamad Malaoui ${ }^{5}$ \\ 1,2,3 Laboratory of Energy Engineering, Materials and systems, National School of Applied Sciences, \\ Ibn Zohr University, B.P. 1136 Agadir, Morocco \\ ${ }^{1,5}$ Laboratoire Interdisciplinaire de Recherche en Sciences et Techniques (LIRST), Faculté Polydisciplinaire, \\ Université Sultan Moulay Slimane, B.P 592, Béni Mellal, Morocco \\ ${ }^{4}$ Laboratoire TIAD, Université Sultan Moulay Slimane, B.P 592, Béni Mellal, Morocco
}

\begin{tabular}{l} 
Article Info \\
\hline Article history: \\
Received Sep 27, 2016 \\
Revised Nov 27, 2016 \\
Accepted Dec 20, 2016 \\
\hline
\end{tabular}

\section{Keyword:}

Electrical parameters Extracting photovoltaic cell Measurement factors Newton-raphson method Single-diode model

\begin{abstract}
In this paper, we study the influence of external factors on the measurement for the current-voltage (I-V) characteristic of the photovoltaic cell. These factors are the size of the number of measurements, the range of the cell generated voltage and the influence of measures step and mode combination of photovoltaic cells (parallel, serial, or hybrid). The main extracted parameters solar cell are the photocurrent $\mathrm{I}_{\mathrm{ph}}$, the reverse diode saturation current $\mathrm{I}_{0}$, the ideality factor of diode $\mathrm{n}$, the series resistance $\mathrm{R}_{\mathrm{s}}$ and the shunt resistance $R_{\mathrm{sh}}$. A method for finding these parameters, according to the single-diode model, was developed by Newton-Raphson's method using Matlab. To assess the accuracy of this method, measured and calculated I-V characteristics were compared with provided data by the manufacturer at standard test condition (STC). The measurement results showed that these parameters are highly dependent on these four factors.
\end{abstract}

Copyright $(2017$ Institute of Advanced Engineering and Science. All rights reserved.

\section{Corresponding Author:}

El Hadi Chahid,

Laboratory of Energy Engineering, Materials and systems,

National School of Applied Sciences, Ibn Zohr University,

B.P. 1136 Agadir, Morocco.

Email: chahid2016@yahoo.com

\section{INTRODUCTION}

The photovoltaic solar energy is one of the most used and promising resources in the renewable energy domain. The conversion of photovoltaic energy is performed by cells based on semiconductors such as silicon, which exploits the photovoltaic effect. The operation of these cells is described generally by the I$\mathrm{V}$ characteristic which provides the information on the mechanisms of intern electric transport and the technological steps imperfections of their fabrications [1], [2]. This characteristic depends on many intrinsic electrical parameters, that are the photocurrent $\mathrm{I}_{\mathrm{ph}}$, the saturation current $\mathrm{I}_{0}$, the ideality factor $\mathrm{n}$, the $\mathrm{R}_{\mathrm{s}}$ series and $\mathrm{R}_{\mathrm{sh}}$ shunt resistances [3], [4].

The accuracy determination of these electrical parameters allows to understand and explain certain physical phenomena like the degradation of the layers that constitute the photovoltaic cells (PVC), the lifetime of minority charge carriers, the energy efficiency, ... etc. [5], [6]. Normally, several methods have been proposed for the extraction of these parameters using the single-diode model which is very sufficient to describe the electrical functioning of the cell [7], [8].

The purpose of this paper is to study the impact of extrinsic factors on the I-V characteristic measurements. That is, to study the influence of the size of the measurements basis, the distribution and the ranges of the output voltage of the solar cell and the types of the combination of the different cells that form 
the solar modules. In general, these factors are often neglected by researchers in the field of electrical modeling and identification of the photovoltaic electrical parameters, especially in the phase of the I-V electrical characteristic measurements, which is the main source of electrical and physical information related to PVC [9], [10].

\section{ELECTRICAL MODELING}

The mathematical model that describes the photovoltaic cell is determined by that of PN junction. We add to it the photocurrent $\mathrm{I}_{\mathrm{ph}}$ which is proportional to the irradiation and also a term that modulate electric intern phenomena. The given current I from the cell is written as follows [11].

$$
\mathrm{I}=\mathrm{I}_{\mathrm{ph}}-\mathrm{I}_{0}\left(\exp \left(\frac{\mathrm{V}+\mathrm{R}_{\mathrm{s}} \mathrm{I}}{\mathrm{nV_{ \textrm {th } }}}\right)-1\right)-\frac{\mathrm{V}+\mathrm{R}_{\mathrm{s}} \mathrm{I}}{\mathrm{R}_{\mathrm{sh}}}
$$

with:

$\mathrm{I}_{\mathrm{ph}}$ : Photocurrent current (or a generated current from irradiation).

$\mathrm{I}_{0}$ : Diode saturation current.

$\mathrm{R}_{\mathrm{s}}$ : Series resistance.

$\mathrm{R}_{\mathrm{sh}}$ : Shunt resistance.

$\mathrm{n}$ : Ideality Factor of diode.

$\mathrm{V}_{\text {th }}$ : Thermal voltage given by, $\left(\mathrm{V}_{\mathrm{th}}=\frac{\mathrm{K}_{\mathrm{B}} \cdot \mathrm{T}}{\mathrm{q}}\right)$.

$\mathrm{K}_{\mathrm{B}}$ : Boltzmann's constant $\left(\mathrm{K}_{\mathrm{B}}=1.38 \times 10^{-23} \mathrm{~J} . \mathrm{K}^{-1}\right)$.

$\mathrm{q}$ : Electrical charge of the electron $\left(\mathrm{q}=1.6 \times 10^{-19} \mathrm{C}\right)$.

$\mathrm{T}$ : Temperature of the cell expressed by ${ }^{\circ} \mathrm{K}$.

Under illumination, a solar cell can be modulated by the electrical circuit with a single diode, represented in the Figure 1 [12]:

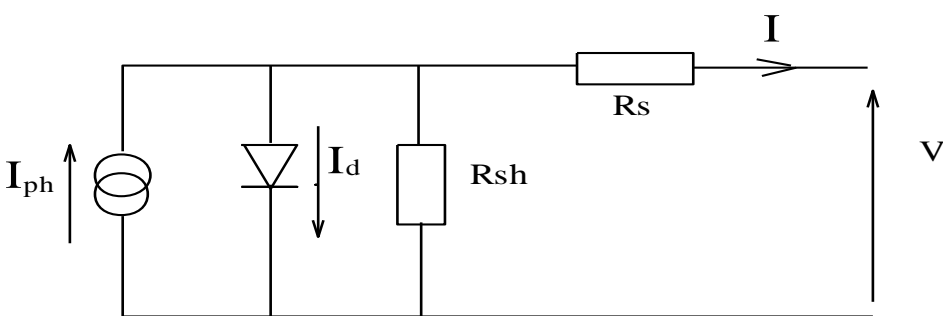

Figure 1. Equivalent Electric Circuit of a PVC

\section{IDENTIFICATION OF PVC PARAMETERS}

In order to understand the physicals mechanisms produced within the interior of the solar cell; there are various parameters that specify these phenomena. Many methods have been proposed for the identification of these parameters, not only for increasing the efficiency of the photovoltaic cell, but also to be able to simulate its comportment and optimize their different parameters.

In our work, we use the model of a single exponential of the PN junction for the PV cell; formulated in the equation (1). This model depends on five electrical parameters such as, the photocurrent $\left(\mathrm{I}_{\mathrm{ph}}\right)$, the reverse saturation current of diode $\left(I_{0}\right)$, the series resistance $\left(R_{s}\right)$, the shunt resistance $\left(R_{s h}\right)$ and the ideality factor (n).

The most used methods to extract electrical parameters are:

a. The method of least square [13].

b. Newton's method [14].

c. The Levenberg Marquardt's method [15].

The identification method that we use is based on the Newton's algorithm to find the final values of these parameters. This algorithm does not normally converge when the initial parameters $\left(\mathrm{R}_{\mathrm{s}}, \mathrm{R}_{\mathrm{sh}}, \mathrm{I}_{\mathrm{ph}}, \mathrm{I}_{0}\right.$ and $n$ ) are not well chosen. Indeed, to estimate these parameters, we used the bouzid's method [16] at the beginning of this algorithm. 
Newton's method use an algorithm which search for the approximations of the roots of function $f(x)=0$. This method develope the I-V model using Taylor's formula in the order 1 around an optimal point $\mathrm{f}(\mathrm{V}, \mathrm{I})=0$ as the following expression:

$$
\mathrm{f}(\mathrm{I}, \mathrm{V})=\mathrm{I}-\mathrm{I}_{\mathrm{ph}}+\mathrm{I}_{0}\left(\exp \left(\frac{\mathrm{V}+\mathrm{R}_{\mathrm{s}} \mathrm{I}}{\mathrm{n} \mathrm{V}_{\mathrm{th}}}\right)-1\right)+\frac{\mathrm{V}+\mathrm{R}_{\mathrm{s}} \mathrm{I}}{\mathrm{R}_{\mathrm{sh}}}
$$

For a given voltage $\mathrm{V}$ the current I is given by the root of equation (2), where "I" is expected to be the single root. In order to determine it, we start with the initial value $I_{i}$, the following iteration is executed:

$$
I_{i+1}=I_{i}-f\left(I_{i}\right) / f^{\prime}\left(I_{i}\right)
$$

The iteration stops if a suitable condition is met. In the case above the absolute difference of two succeeding values of the iteration is used :

$$
\left|\mathrm{I}_{\mathrm{i}+1}-\mathrm{I}_{\mathrm{i}}\right|<\varepsilon
$$

Using the fitting technique of an experimental curve with a theoretical curve modulating the equation (1), we are able to determine intrinsic parameters of a solar cell. This technique focuses on minimizing the sum of the squares of the errors used in the objective function, defined as:

$$
\chi(\varphi)=\sum_{i=1}^{N}\left(I_{i}^{\exp }-I_{i}\left(V_{i}, \varphi\right)\right)=\sum_{i=1}^{N} R_{i}^{2}(\varphi)
$$

a. $\varphi$ is a number of unknown parameters: $\varphi\left(\mathrm{I}_{\mathrm{ph}}, \mathrm{I}_{0}, \mathrm{n}, \mathrm{R}_{\mathrm{s}}, \mathrm{R}_{\mathrm{sh}}\right)$

b. $\quad R_{i}$ is a Residual error between experimental values $I_{i}^{\exp }$ and calculated values $I_{i}\left(V_{i}, \varphi\right)$.

c. $\mathrm{N}$ is a Number of the measurement points.

d. $\mathrm{I}_{\mathrm{i}}$ and $\mathrm{V}_{\mathrm{i}}$ are respectively the measured current and voltage at the $\mathrm{N}^{\mathrm{i}}$ point of measured data.

We have used Newton's algorithm for the minimization of the objective function $\chi$. The five optimal values of the parameters $\varphi$ are evaluated by Newton's iterations:

$$
\varphi_{\mathrm{j}}=\varphi_{\mathrm{j}-1}-\left[\mathrm{J}\left(\varphi_{\mathrm{j}-1}\right)\right]^{-1} \mathrm{f}\left(\varphi_{\mathrm{j}-1}\right)
$$

$\mathrm{J}(\varphi)$ : Jacobian matrix and their elements are defined as the derivatives of the current concerning the five parameters mentioned before $\left(\frac{\partial \mathrm{I}}{\partial \varphi}\right)_{\varphi=\varphi_{\mathrm{i}}}$

\section{MEASURES AND USED TECHNIQUES}

\subsection{Experimental assembly}

The measuring device comprises an electronic card based on a microcontroller (Arduino $\mu \mathrm{C}$ ), a PC computer and an interface electronic card connected to the PV module. The computer is equipped with the LabView software for acquisition of current I and voltage $\mathrm{V}$ of the module through the Arduino analog inputs $\mathrm{A} 0$ and A1. Electromechanical relays are controlled by the $\mu \mathrm{C}$, and allow changing PV load through binary / decimal decoders.

Measurement voltage $\mathrm{V}$ of PVC is performed by a voltage divider created by resistors, and operational amplifiers which provide impedance matching. In general, the maximum voltage at the output of the PV module is about 20 volts, so we use a ratio of $1 / 4$ to the voltage divider to get the maximum 5 volts on the analog input of $\mu \mathrm{C}$.

To increase the accuracy of the measurement of the current, an amplifier gain of 2 is adjusted and used at the output of this sensor. Electrical measurements are taken using an automatic solar tracker, which 
we developed to ensure a relatively constant light intensity for these measures [16]. Figure 2 is shows used experimental assembly.

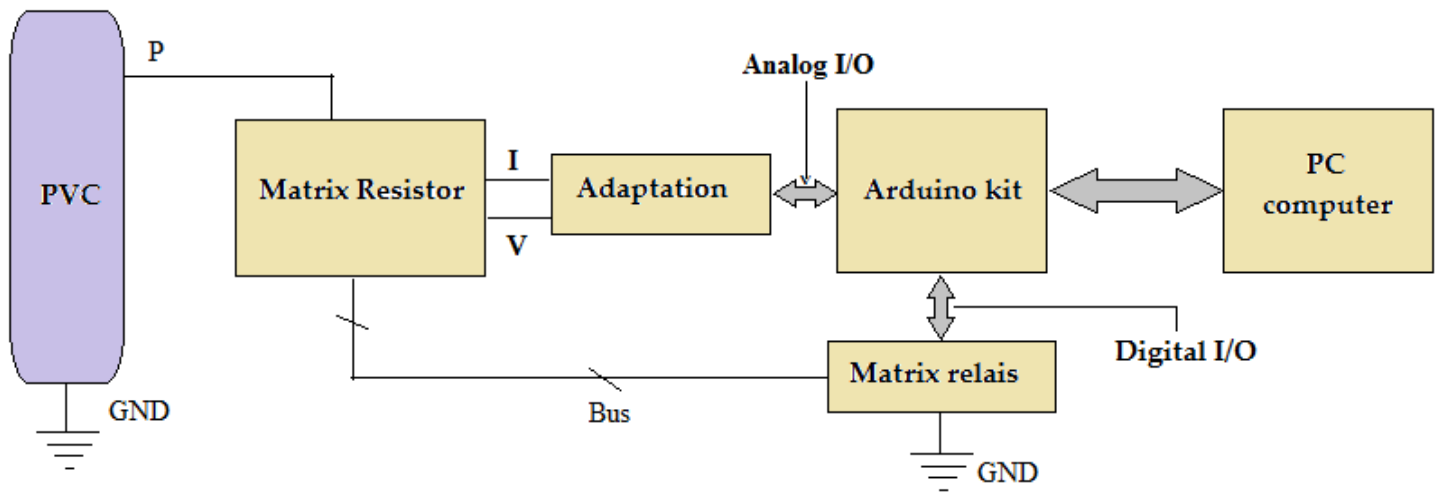

Figure 2. Used Experimental Assembly

\subsection{Measurement technique}

The test experiments realized are performed according to an assembly of measures achieved from solar panel constituted from silicon polycrystalline "Solarex MSX60". This module is composed of 36 solar cells which are combined parallel at the Standard Test Condition STC of the irradiation and the temperature. Our research group has already worked on optimizing these measures by improving methods and instruments of the optimal measuring I-V of a solar panel [17].

This paper highlights the effects of the impact of the four major factors on the accuracy of the intrinsic parameters of the electric model $\left(\mathrm{R}_{\mathrm{s}}, \mathrm{R}_{\mathrm{sh}}, \mathrm{I}_{\mathrm{ph}}, \mathrm{I}_{0}\right.$ and ideality factor $\left.\mathrm{n}\right)$. These factors are:

1. The size of the measured data base on the I-V characteristic, which means the number $(\mathrm{N})$ of measurement points for measuring the $\mathrm{I}-\mathrm{V}$ characteristics of solar cells. The number $(\mathrm{N})$ of the measurements realized during the experience of $\mathrm{I}-\mathrm{V}$.

2. The nature and the values of the step of the measures $(\mathrm{Ij}, \mathrm{Vj})$ in a characteristic.

3. The distribution of the measures on the different zones of the voltage $\mathrm{V}$ of the characteristic. Three zones are precised; the zone 1, for low voltages, the zone 2 for medium voltages and the zone 3 is related to the high voltages.

4. The association of the connection of the PV cells in the interior of a PV module.

In our case, we have studied the effect of two types association of the cells. In the first side, the series association of two PVC is examined, followed by a test on another parallel association of the cells. The validation and the interpretation of the results discovered are made through a comparing between these values with a reference [17]. Taking into account that during the steps of these measures, we have respected the acquisition technique and the filtering without noise which is developed by our research group [10], [18]. After determining the optimal factors that give a better measure, a deep study is currently underway by our research group to determine the relation between of the minorities carriers lifetime of electrons and holes $\tau_{n}$ and $\tau_{\mathrm{p}}$ respectively and intrinsic electrical parameters.

\section{RESULTS AND DISCUSSION}

Before studying the impact of these factors on the reliability and the accuracy of the PVC electrical parameters, the device and the developed program were tested and their results were compared with a mathematic model (equation 1). The simulation and measured results of I-V characteristics are compared and shown in Figure 3.

From the first sight, this curve provides an enough confidence on the tools of taken measures during this work. It is noted that, there is a correlation between the measured data and the electrical model of the single diode, within the whole range of the applied voltage which is changed from $0 \mathrm{~V}$ to $\mathrm{V}_{\mathrm{oc}}=21.1 \mathrm{~V}$ in 40 measures data base. Indeed, to have more details about of the influence of measured numbers $(\mathrm{N})$ and divided step $(\Delta)$ of these measures, tests are carried on the same photovoltaic cell by varying these two parameters. 


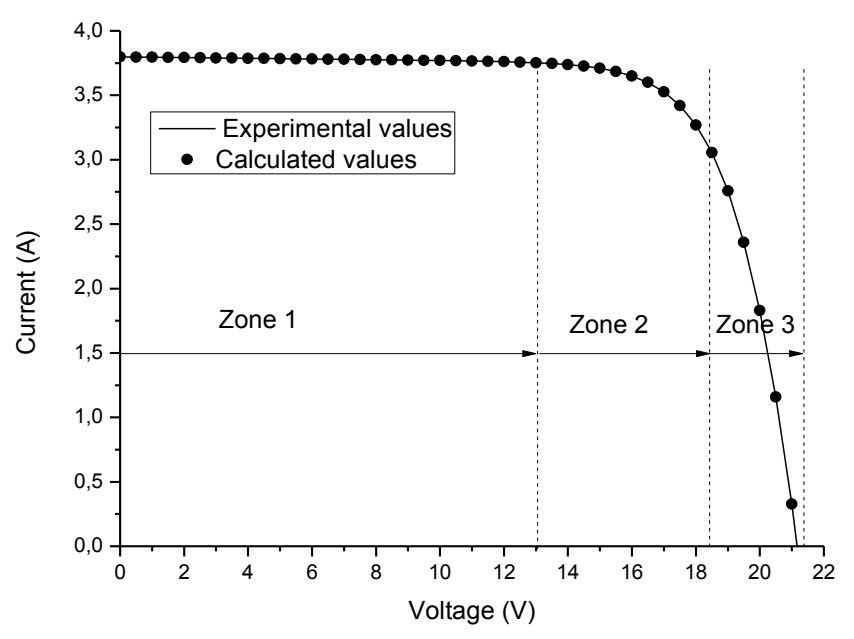

Figure 3. Experimental and Calculate of PVC Characteristics

\subsection{Effect of the Measurements Number (N)}

\subsubsection{Measures with a Constant Step}

A constant step of taken measures $(\mathrm{Ij}, \mathrm{Vj})$ are chosen in this level. The measurements were carried from the whole range of voltages $\left[0 \mathrm{~V}-\mathrm{V}_{\mathrm{oc}}\right]$, through a step $\Delta=\frac{\mathrm{V}_{\mathrm{oc}}}{\mathrm{N}}$ for each size of the measured data base. Eelectrical parameters are calculated by the developed program [16], and the results are shown in the Figure 4. The calculated error $\mathrm{R}$ as a function of the number of the measures $(\mathrm{N})$ is presented in the Table 1.

Table 1. Measurement Error with Number $(\mathrm{N})$

\begin{tabular}{ccccccccccc}
\hline $\mathrm{N}$ & 20 & 40 & 60 & 90 & 110 & 150 & 160 & 180 & 200 & 220 \\
\hline $\mathrm{R}\left(\times 10^{-6}\right)$ & 0.67 & 0.06 & 8.7 & 2.2 & 0.63 & 2.8 & 11.5 & 10.4 & 3.52 & 2.0 \\
\hline
\end{tabular}
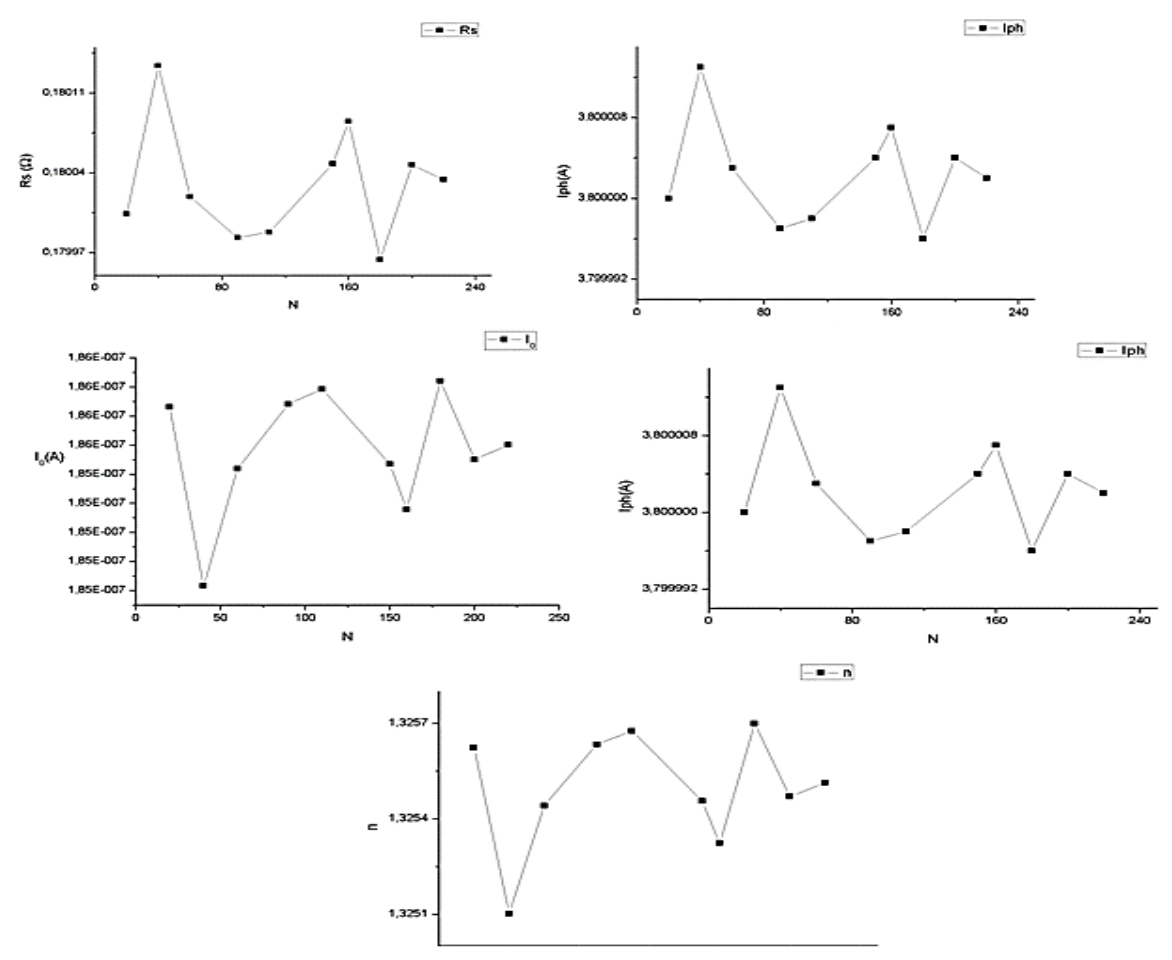

Figure 4. Variation of PVC Electrical Parameters with N 
This table shows a minimum value of the error $\mathrm{R}$ which fits with a number $\mathrm{N}=40$ of measurements. The Figure 3 presents a minimum at $N=40$ concerning the three parameters $R_{\text {sh }}, I_{0}$ and $n$, whereas the other parameters $\mathrm{R}_{\mathrm{sh}}$ and $\mathrm{I}_{\mathrm{ph}}$, show a maximum at $\mathrm{N}=40$.

Meanwhile, this result guides us to minimize the number of I-V measurements, in order to save time and energy while measuring. Furthermore, it allows us to save the memory space for digital devices of acquisition. Indeed, in contrary to what we believe that a big number of measurements are frequently required. A reduced number of measurements is largely sufficient and it is sometimes optimal in order to discover specific results of the electrical parameters. This is explained by the reduction of the fluctuations and the minimization of the errors produced through a large data base of measurements. On the other hand, concerning the values $(\mathrm{N})$ which are greater than 40, the accuracy of PVC electrical parameters are not linear. So, instead of using larger sizes of the measures of the I-V characteristic, we take a minimum number of measurement $(\mathrm{N}=40)$ as in our case.

\subsubsection{Measures with a variable step}

The measuring of the I-V characteristic at this level was examined by taking a variable step $(\Delta)$. Indeed, the three zones have been fixed:

$\Delta_{1}=0.4 \mathrm{~V}$ : Low voltages domain, as $\left(0<\mathrm{V}<5 / 8 \mathrm{~V}_{\text {oc }}\right)$,

$\Delta_{2}=0.01 \mathrm{~V}$ : Medium voltages domain, as $\left(5 / 8 \mathrm{~V}_{\mathrm{oc}}<\mathrm{V}<7 / 8 \mathrm{~V}_{\mathrm{oc}}\right)$,

$\Delta_{3}=0.2 \mathrm{~V}$ : High voltages domain, as $\left(7 / 8 \mathrm{~V}_{\mathrm{oc}}<\mathrm{V}<\mathrm{V}_{\mathrm{oc}}\right)$.

The electrical parameters extracting $\left(\mathrm{R}_{\mathrm{s}}, \mathrm{R}_{\mathrm{sh}}, \mathrm{n}, \mathrm{I}_{\mathrm{ph}}\right.$ and $\left.\mathrm{I}_{0}\right)$ are calculated and presented in Table 2.

Table 2. Comparison of the Intrinsic Parameters with the Variable and Constant Step

\begin{tabular}{cccccc}
\hline Electrical parameters & $\mathrm{R}_{\mathrm{s}}(\Omega)$ & $\mathrm{R}_{\mathrm{sh}}(\Omega)$ & $\mathrm{I}_{\mathrm{ph}}(\mathrm{A})$ & $\mathrm{I}_{0}(\mathrm{~A})$ & $\mathrm{n}$ \\
\hline Variable step $(\Delta)$ & 0.179 & 360.123 & 3.7999 & $1.85 \times 10^{-7}$ & 1.325 \\
Constant step $(\Delta)=0.5 \mathrm{~V}$ & 0.180 & 360.020 & 3.8000 & $1.85 \times 10^{-7}$ & 1.325 \\
Reference $[18]$ & 0.180 & 360.002 & 3.8119 & $1.85 \times 10^{-7}$ & 1.360 \\
\hline
\end{tabular}

From these values, it is found that the variation of the step $(\Delta)$ of the voltage does not have too much effect on the electrical parameters of the cell. Therefore, it is recommended to work with a regular step to optimize the electrical measurement chain. A variable step $(\Delta)$ requires additional time to the processor which rotates the calculation algorithm. Indeed, the program is slower and requires more storage space for the iterations. Therefore, the calculation is more complicated and makes the possibility of divergence of the program.

\subsection{Effect of the bias voltage ranges:}

We took the best measures which correspond to the 40 measures in Table 3.

Table 3. Intrinsic Electrical Parameters Depending on the Variable Voltage Range

\begin{tabular}{cccccc}
\hline Voltage Range $(\mathrm{V})$ & $\mathrm{R}_{\mathrm{s}}(\Omega)$ & $\mathrm{R}_{\mathrm{sh}}(\Omega)$ & $\mathrm{I}_{\mathrm{ph}}(\mathrm{A})$ & $\mathrm{I} 0$ & $\mathrm{n}$ \\
\hline Low [0-5/8Voc] & 54.681 & 304.732 & 4.4796 & $1.04 \times 10^{-108}$ & 0.966 \\
Averages [5/8Voc-7/8Voc] & 1.895 & 27.681 & 4.4964 & $1.02 \times 10^{-23}$ & 0.504 \\
High [7/8Voc -Voc] & 0.330 & 0.534 & 40.1492 & $2.33 \times 10^{-52}$ & 0.193 \\
Reference [18] & 0.180 & 360.002 & 3.8119 & $1.85 \times 10^{-7}$ & 1.360 \\
\hline
\end{tabular}

At a low voltage domain, the obtained electrical parameters show that the optimal parameters are those of $\mathrm{R}_{\mathrm{sh}}$, $\mathrm{I}_{\mathrm{ph}}$ and $\mathrm{n}$ according to the output voltage ranges of the solar cell module. At a medium voltage domain, the optimal parameter is that the saturation current $\mathrm{I}_{0}$. At high values of voltage, the optimal value is that of the series resistance $\mathrm{R}_{\mathrm{s}}$.

\subsection{Effect of PVC association:}

The used photovoltaic cell in this work is that of silicon [17]. The effect of the mounting type of these solar cells was studied in the case of a series connection, and then in parallel. The results are shown in Table 4. 
Table 4. Intrinsic Electrical Parameters Depending on the Type of Association

\begin{tabular}{cccccc}
\hline solar cell mounting & $\mathrm{R}_{\mathrm{s}}(\Omega)$ & $\mathrm{R}_{\mathrm{sh}}(\Omega)$ & $\mathrm{I}_{\mathrm{ph}}(\mathrm{A})$ & $\mathrm{I}_{0}(\mathrm{~A})$ & $\mathrm{n}$ \\
\hline One cell & 0.106 & 872.398 & 0.1023 & $6.30 \times 10^{-8}$ & 1.416 \\
Two series of cells & 0.213 & 1744.843 & 0.1023 & $6.30 \times 10^{-8}$ & 2.833 \\
Two paralleled cells & 0.038 & 503.329 & 0.2045 & $1.96 \times 10^{-7}$ & 1.460 \\
Reference [18] & 0.180 & 360.002 & 3.8119 & $1.85 \times 10^{-7}$ & 1.360 \\
\hline
\end{tabular}

Based on the extracted values from the Newton's method, we found that in the case of a series connection, the electrical parameters Rs, Rsh and $n$ having values that are doubled, contrary to the photocurrent $I_{\mathrm{ph}}$ and the saturation current $I_{0}$ remain unchanged. In the case of a parallel association, the parameter $I_{p h}$ is doubled, contrary to the ideality factor $n$ that remains constant and the saturation current $I_{0}$ are significantly increased, whereas the resistances $R_{s}$ and $R_{s h}$ are decreased in a low manner.

\section{CONCLUSION}

In this work, we have studied the sensitivity of the intrinsic electricl parameters of a photovoltaic solar cell (the photocurrent $I_{p h}$, the saturation current $I_{0}$, the ideality factor $n$, the series resistance $R_{s}$ and the shunt resistance $R_{s h}$ ) according, first, to the number of measures $(N)$, second, to the step of the I-V characteristics voltages, third, to the range of voltages in this characteristic and the type of the different cells connection. So, the obtained electrical parameters are relatively depending on the previous factors. Based on what has preceded, we deduce that the minimum number of measurements ( $\mathrm{N}=40$ in our case) is largely sufficient and it is recommended to work with a regular step to optimize the accuracy of the extracted parameters. Relatively to the range of voltages, we must choose the low output voltages in order to achieve an optimal measure of the following parameters $R_{\mathrm{sh}}, \mathrm{I}_{\mathrm{ph}}$ and $\mathrm{n}$. However, the optimal value of the extracted series resistance $R_{s}$ must be made in high bias voltages; while the extracted saturation current $I_{0}$ should be performed in the average voltages. Concerning the influence of different cells connection mode, we observe that the values of electrical parameters $R_{s}, R_{s h}$ and $n$, are approximately doubled in the PVC series combination; whereas, the photocurrent $\mathrm{I}_{\mathrm{ph}}$ also doubled in a parallel association in this study. These last results are in accordance with the theoretical results, while the other results are unexpected and can be exploited to increase the performance of the PVC and their installations.

\section{REFERENCES}

[1] K. Yamaguchi and H. Kodera, "Optimum Design of Triode-Like JFET's by Two-Dimensional Computer Simulation," IEEE Transaction on Electron Devices, vol/issue: ED-24(8), pp. 1069, 1977.

[2] S. M. Sze, "Physics of Semiconductor Devices," John Wiley, New York, 1981.

[3] A. Schenk and U. Krumbein, "Coupled Defect-Level Recombination: Theory and Application to Anamalous Diode Characteristics," Journal of Applied Physics, vol/issue: 78(5), pp. 3185-3192, 1995.

[4] S. Yadir, et al., "Extraction of Solar Cell Physical Parameters Model with Double Exponential from Illuminated IV Experimental Curve," Global Journal of Physical Chemistry, pp 236-240, 2011.

[5] N. F. Mott, "Metal-Insultor Transitions," Second Edition, Taylor \& Francis, London, 1990.

[6] J. S. Kumari and C. S. Babu, "Mathematical Modeling and Simulation of Photovoltaic Cell using MatlabSimulink Environment," International Journal of Electrical and Computer Engineering, vol/issue: 2(1), pp. 26-34, 2012.

[7] A. P. Alivisatos, "Semiconductor Clusters, Nanocrystals, and Quantum Dots," Science, vol. 271, pp. 933-937, 1996.

[8] O. Breitenstein, et al., "Material-Induced Shunts In Multicrystalline silicon solar Cells," Semiconductors, vol/issue: 41(4), pp. 440-443, 2007.

[9] A. Malaoui, et al., "implementation a new approach for modeling and determining the electrical parameters of solar cells," International Journal of Innovation and Applied Studies, vol/issue: 15(2), pp. 329-338, 2016.

[10] A. Malaoui, "New method for improving the quality of electrical measurements: application to the extraction of the intrinsic parameters of the photovoltaic cells," International Journal of Innovation and Applied Studies, vol/issue: 15(2), pp. 375-386, 2016.

[11] M. Louzazni, et al., "Modeling and Simulation of A Solar Power Source for a Clean Energy without Pollution," International Journal of Electrical and Computer Engineering, vol. 3, pp. 568-576, 2013.

[12] T. Ikegami, et al., "Estimation of equivalent circuit parameters of PV module and its application to optimal operation of PV system,” Solar Energy Materials \& Solar Cells, vol. 67, pp. 389-395, 2001.

[13] W. H. Press, et al., "Numerical Recipes in C: The Art of Scientific Computing," 2nd Ed. Cambridge University Press, vol. 9, pp. $362-367,2002$.

[14] T. Easwarakhanthan, et al., "Nonlinear Minimization Algorithm for Determining the Solar Cell Parameter with Microcomputers," International Journal of Sustainable Energy, vol. 4, pp. 1-12, 1986. 
[15] D. Marquardt, “An Algorithm for Least Squares Estimation of Non Linear Parameters," SIAM Journal Of Applied Math, vol. 11, pp. 431-441, 1963.

[16] K. Bouzidi, et al., "Solar cell parameters evaluation considering the series and shunt resistance," Solar Energy Materials \& Solar Cells, vol. 9, pp. 1647-1651, 2007.

[17] D. Bonkoungou, et al., "Modelling and Simulation of photovoltaic module considering single-diode equivalent circuit model in MATLAB," IJETAE International Journal of Emerging Technology and Advanced Engineering, vol/issue: 3(3), 2013.

[18] A. Malaoui, "Implementation and tests of an automatic system to improve electrical energy in photovoltaic installations," International Journal of Innovation and Applied Studies, vol. 8, pp. 328-340, 2014.

\section{BIOGRAPHIES OF AUTHORS}
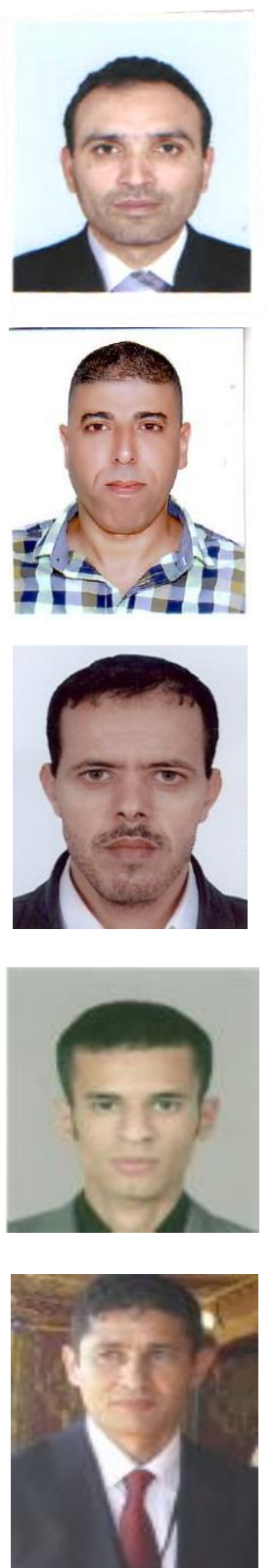

E. Chahid was born in El Jadida, Morocco in 1973. Currently is an Assistant Professor at Regional Center for Careers of Education and Training in Beni Mellal. His area of interest is Photovoltaic system and Electronics Engineering.

E-mail : chahid2016@yahoo.com

M. Idali Oumhand was born in Casablanca, Morocco in 1966. Currently is an Assistant Professor at Regional Center for Careers of Education and Training in Inzegan. His area of interest is Photovoltaic system and Electronics Engineering. Member at LGEMS Laboratory of Energy Engineering, Materials and systems, National School of Applied Sciences ENSA, Ibn Zohr University, Agadir, Morocco.

E-mail : idali4@yahoo.fr

M. Feddaoui is a professor of mechanical engineering at National School of applied Sciences, Ibn Zohr University. He is head of Energy Engineering, Materials and Systems. He received his professor (HDR) degree from Ibn Zohr University in 2011. He has published more than 30 research papers in international journals and more than 50 papers in edited proceedings and actes. He has been working in several fields, such as multiphase flow, phase change, heat and mass transfer, nanofluids.

E-mail :m.feddaoui@uiz.ac.ma

M. Erritali Obtained a Phd in 2013 at the faculty of sciences, Mohamed V Agdal University Rabat. His current interests include developing specification and design techniques for use within Intelligent Network, data mining, image processing, cryptography and Electrical systems. He is currently a professor at the Faculty of Science and Technology, University Sultan Moulay Slimane.

E-mail : mederritali@yahoo.fr

Dr. Abdessamad Malaoui is a Prof. at Polydisciplinary Faculty (Sultan Moulay Slimane University of Béni Mellal). He obtained his PhD. doctorat in electronics \& computer sciences, from University of Provence - France in 2005. He obtained his Habilitation thesis in electronics, computer sciences in 2011. His research interests are in electronics, Industrial computer, $\mu \mathrm{P} \& \mu \mathrm{C}$, renewable energy, PV system performance monitoring.

E-mail : a.malaoui@usms.ma 